What matters to students' success in mathematics? The case of fractions.

Winsløw, Carl

Published in:

Journal of Teaching and Learning in Elementary education

DOI:

10.33578/jtlee.v2i2.7204.

Publication date:

2019

Document version

Publisher's PDF, also known as Version of record

Citation for published version (APA):

Winsløw, C. (2019). What matters to students' success in mathematics? The case of fractions. . Journal of Teaching and Learning in Elementary education, 2(1), 79-90. https://doi.org/10.33578/jtlee.v2i2.7204. 


\title{
What matters to students' success in mathematics? The case of fractions
}

\author{
Carl Winsløw \\ Department of Science Education, University of Copenhagen, Denmark \\ winslow@ind.ku.dk
}

\begin{abstract}
Fractions are at the transition between everyday arithmetic and algebra, and there is hardly any domain of mathematics - not least when it comes to applied mathematics where fractions do not appear. What is actual the significance of this subject in elementary education and beyond? In what sense are teachers a key to students' learning in this area? What must teachers in elementary school know about it? What systemic conditions are important or even necessary to teachers' and students' success in teaching and learning fractions? What kind of research can enlighten us on these matters?
\end{abstract}

Keywords: fractions, numbers, mathematics teacher knowledge, Klein

\section{INTRODUCTION}

Mathematics is taught in all grades at practically any school throughout the world, and it is usually one of the three subjects to which most classes are devoted. The rationale is well known: mathematics permeates not just social life but is also, and increasingly, indispensable in further education - from nursing to business and engineering.

At the same time, a number of countries struggle with poor results in international surveys of student performance, such as the PISA survey conducted by the OECD. Governments concerned with students' failure in mathematics is no novelty, and corresponding political initiatives have existed for more than a century (Kilpatrick, 1992). Mathematics education research has partly grown out of such initiatives, but also resulted from efforts to meet certain intellectual and practical needs of mathematicians and teacher educators.

In this paper, we provide a synthesis of research on one particular subject from elementary school mathematics: fractions. Fractions appear to be a leverage point for central parts of what has been called "the mathematics problem". The paper also seeks to exemplify the wide range of approaches which mathematics education research can more generally offer on this problem. We conclude by pointing out a need for better connections between these different approaches, which range from purely mathematical investigations of 
Journal of Teaching and Learning in Elementary Education (JTLEE)

Vol. 2 No. 2 August 2019

(C)All rights reserved

Printed in Indonesia
ISSN (Print) : 2615-4528

ISSN (Online) : 2622-3023

DOI: http://dx.doi.org/10.33578/jtlee.v2i2.7204 school mathematics, to large scale quantitative surveys.

\section{WHY FRACTIONS?}

Since the early 1970 s, a series of quantitative studies have been undertaken in the United Kingdom and in the United States, to investigate how mathematical learning at early stages affect mathematical learning at later stages. A consistent finding is that elementary school students' knowledge of fractions and of division uniquely predicts those students' knowledge of algebra and overall mathematics achievement in high school, 5 or 6 years later, even after statistically controlling for other types of mathematical knowledge, general intellectual ability, working memory, and family income and education (Siegler et al, 2012). This means that when submitting a group of children of about 10 years of age to a test which involves knowledge of fractions and other items, and then submitting the same group of children to another test of mathematical proficiency 6 years later (with items suitable for 16 years old), one identifies a strong correlation. Thus, there appears to be a close connection between the knowledge of fraction arithmetic and division at the age of 10, and ageappropriate mathematical proficiency at the age of 16 . This correlation cannot be explained by the other factors mentioned; for instance, it is not simply a consequence of high-achievers being more intelligent, or coming from richer families. This is not the result of a single study, but a consistent result of many similar studies. It is also confirmed by more mathematical considerations, which will be further developed in the next section. But the importance of the result only becomes clear when combined with the fact, mentioned and substantiated in the same paper (Siegler et al, 2012), that high school students' mathematics achievement predicts college matriculation and graduation, earlycareer earnings, and earnings growth. Thus, a student who underachieves in the domain of fractional arithmetic at the age of ten, is statistically likely to fail in mathematics at high school level, then fail to enter or succeed to complete a relevant higher education degree, subsequently get a low paid job, and finally contribute less to society. Taken to an even higher level, and pushing the argument to a political level: societies which fail to provide their population with solid elementary education in the domain of fractions and division, may face the prospects of a weaker economy than they would otherwise have.

\section{THE KEY ROLE OF TEACHERS}

We have just encountered a result from what is sometimes called the cognitive approach to mathematics. It is about identifying, at the level of individuals, how mathematics is learned, including important dependencies such as the one between fractional arithmetic and more advanced mathematical subjects. Methods are often quantitative, although the construction of appropriate items on a mathematical subject 
naturally also requires expertise in the area of mathematics itself. However, they stop at the level of measuring individual learning, and say nothing about how that learning can be improved. For this, we have schools and, as far as the learning of mathematics is concerned, the scholarly field of mathematics education.

The existence of schools in our societies testify to the experience and belief that mathematical knowledge can be furthered by such institutions, and help students to acquire important knowledge which everyday experience would not provide them with. General schooling of the entire population dates back to the $19^{\text {th }}$ century in most countries, and is nowadays not questioned - on the contrary, the quality of students' performance is regularly measured by organizations such as the OECD, and the results are immediately interpreted as measures of how well the schools in a given country perform. This is not least the case in a subject like mathematics, where it is fairly easy to devise reliable tests of students' knowledge - based on the cognitive approach that we just mentioned. However, in the event of unsatisfactory results, we must turn to mathematics education research for clues about what measures to take to improve the performance of schools. Indeed, most Western nations have invested massively in this area over the past 30 years.

However, mathematics education research has much older roots, going back to where one would expect the basic problems of the field to become evident: namely, the $19^{\text {th }}$ century, where institutions were set up to provide the general population with fundamental knowledge in mathematics, as well as in other disciplines. It is interesting to note that some of the main points of this paper were observed already by an early pioneer in the field, who was also an outstanding mathematician: Felix Klein (1849-1925).

Klein was concerned with the proper education of mathematics teachers. He was a humanist in the classical sense i.e. as a scholar who believes in the value of education to form citizens who are able to reason and act in full freedom, and thereby contribute to the good of their fellow humans. Unlike many of his (and our) contemporary mathematicians, he was not only a specialist in one specialized field - although he indeed was that, too -but he also held a broad and deep knowledge of mathematics as a whole, and a vision of how teachers and teaching could best make the basics of the discipline accessible to students. His main ideas to this end are developed in the three volume treatise Elementharmathematik vom höheren Standpunkte aus (Fundamental Mathematics from a Higher Standpoint, originally published in German in 1908, with the most recent and complete translation into English being Klein, 2016). In the famous preface to the first volume, which bears the subtitle "Arithmetic, Algebra and Analysis", he first points out the shortcomings of how mathematics teachers (for high school) 
were trained at his time: namely, by being exposed to a number of modern fields of mathematics, without any concern for their subsequent activity as teachers. Klein, naturally, does not oppose the idea that future teachers must know their subject well, and even have knowledge of more advanced mathematics that they will not be asked to teach directly. His vision for the preparation of mathematics teachers is well captured by the title: the teacher must not only know the elementary subjects they teach, but they must develop a "higher standpoint", a more advanced vision, of this knowledge, based on the more advanced mathematics they have studied at university. And the three volumes put this seemingly vague vision into firm forms, as he develops the mathematics of both primary and secondary school (of his time, but in fact also of today) while constantly drawing on both historical and contemporary insights from more advanced subjects. We will return to, and extend, how he applies this to fractions, in the following section.

The general conviction of Klein, that the proper - and ambitious - education of mathematics teachers is indeed a foundational one in the field of mathematics education research. One of the most important rationales for the field is to provide a suitable knowledge basis for mathematics teacher education. And indeed, most contemporary researchers in the field are also teacher educators.
It has been confirmed by numerous later studies, such as the TEDS-M study (Tatto et al, 2018), as well as other large-scale studies, that there are strong connections between the contents of mathematics teacher education, the quality and extent of teachers' mathematical knowledge, and their students' achievements, at country level. Other studies have looked at the individual teacher level (eg. Hill, Rowan and Ball, 2005). These studies still apply a cognitive approach in the sense that they identify structures and correlations based on test of human knowledge, which leaves mostly broad hypotheses as to the burning question of what should be done to improve teachers' knowledge and, as a consequence, their students' results. It goes without saying that any claim of causal relations, based on statistical correlation, is open to critique.

But there are other studies, more anthropological and qualitative in nature, which lend support to the hypothesis that teachers' knowledge and good conditions for its development (through initial and in-service practices) is of decisive importance. One of the most celebrated studies in the TIMSS video study and corresponding research on teachers' professional development, exposed in the widely known volume The Teaching Gap by Stigler and Hiebert (1999). In this volume, the authors note the striking difference in teaching approaches found when comparing "arbitrary" mathematics lessons in Japan and the United States, and links this with the professional learning opportunities that are available 
to teachers in the two countries. In particular, they stipulate that the superior professional knowledge of Japanese mathematics teachers is not only a result of better initial training, but also of opportunities to develop their knowledge of mathematics and its teaching through in-school practices such as lesson study. It is important not to simplify their argument, though: the superior results of Japanese school children is the outcome of systemic differences, which comprise also more consistent curricula and teaching materials, which on their part depends on the knowledge produced by teachers in schools, and in interaction with other agents such as university researchers.

Mathematics teacher knowledge is indeed a difficult object to model and study. In particular, it has both generic and very specific aspects. For reasons exposed in the first section, we may want to focus on specific aspects of the teachers' competence, such as what goes into the teaching of fractions. In this area, the recent doctoral dissertation of Zetra Putra (2018), investigating and comparing the Indonesian and Danish teacher students' knowledge of fractions, is of great interest. Putra makes use of an intricate methodology to model and measure mathematics teacher knowledge, based on mathematical and didactical praxeologies (Chevallard, 1999) and hypothetical teacher tasks (Durand-Guerrier, Winsløw and Yoshida, 2010). A major outcome is to point out that Indonesian teacher students appear to have a purely instrumental knowledge of the operation with and order structure of rational numbers, especially when these are represented as fractions. Both they and the Danish students have a very limited inventory of strategies for teaching the same topics, and an almost total lack of "advanced viewpoint" regarding the theoretical aspects of student tasks. Putra speculates that hypothetical teacher tasks may be put to direct use in teacher education, and it will be interesting to learn of the results from his announced investigations of this - very concrete and practical - proposal for teacher education on this particular point.

\section{CONTENT ANALYSIS}

Having established that fractions and division do indeed represent a non-trivial challenge for the teaching of mathematics at primary level, and that improving teaching and its results on this delicate matter depends on teachers' mathematical and didactical knowledge of the subject matter, let us take a closer look at what fractions are all about.

Klein (2016, vol. I, pp. 31ff) observed that already at his time, two approaches seemed to compete: a formal one and an applied one.

The formal approach presents fractions as symbols of type $\frac{a}{b}$ where $a$ and $b$ are integers, and $b \neq 0$. One further stipulates that $\frac{a}{b}$ and $\frac{c}{d}$ should be considered equivalent if $a d=b c$. Fractions under this equivalence are called rational numbers. Subsequently one verifies that 


$$
\frac{a}{b}+\frac{c}{d}=\frac{a d+b c}{b d}, \frac{a}{b} \cdot \frac{c}{d}=\frac{a c}{b d}
$$

defines operations on the rational numbers, based on the (already familiar) operations on the integers. One then shows that the set $\mathbb{Q}$ of rational numbers satisfy the axioms of a field:

(A1) $q+r=r+q$ for $q, r$ in $\mathbb{Q}$

(A2) $q+(r+s)=(q+r)+s$ for all $q, r, s$ in $\mathbb{Q}$

(A3) There is a rational number 0 so that $q+0=q$ for all $q$ in $\mathbb{Q}$

(A4) For all $q$ in $\mathbb{Q}$ there exists ${ }^{\wedge} q$ in $\mathbb{Q}$ so that $q+{ }^{\wedge} q=0$

(M1) $q \cdot r=r \cdot q$ for $r, q$ in $\mathbb{Q}$

$(\mathrm{M} 2) q \cdot(r \cdot s)=(q \cdot r) \cdot s$ for $q, r, s$ in $\mathbb{Q}$

(M3) There is 1 in $\mathbb{Q}$ so that for all $q$ in $\mathbb{Q}$ one has $q \cdot 1=q$

(M4) For all $q$ in $\mathbb{Q}$ there exists $q^{*}$ in $\mathbb{Q}$ so that $q^{*} \cdot q=1$.

(D) $q \cdot(r+s)=q \cdot r+q \cdot s$ for all $q, r, s$ in $\mathbb{Q}$

It continues with similarly formal definitions of the order relation, which turns this field into a dense and completely ordered field. Here, fractions are merely symbols, but all rules governing their use are explicitly defined or proved.

The more applied approach starts from students' intuition on measurable quantities, where at least simple fractions such as $\frac{1}{2}$ and $\frac{1}{4}$ will be familiar to students from social life contexts. It then develops arithmetic and order structure based on a mixture of appeal to the first intuitions of children, and rules that are mainly taught by examples, where cases such as

$$
\frac{2}{15} \cdot \frac{9}{10}=\frac{3}{25}
$$

will most likely have to be based on rules that are neither clear nor meaningful, and which some pupils find it hard to accept and remember.

Klein also mentions a third, somewhat complementary approach, based on a visualization of the integers as points on a doubly infinite "continuous" line, where in fact all fractions can be progressively represented as intermediate points (se Fig. 1).

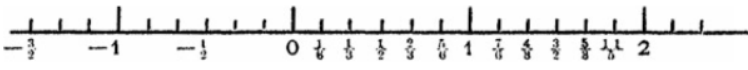

Figure 1: Fractions on a line (Source: Klein, 2016/1908, vol. I, p. 33).

This representation of numbers on a line has several advantages. The order structure is clearly visible and corresponds to the left-right principle for ordering the integers. The "number line" also helps to accept the difficult density property of the set of rational numbers. The operations can be developed in a somewhat intuitive way, related to "length" and repeated addition - again, extending the integer case. One needs, however, some caution, as multiplication of rational numbers cannot, in general, be conceived of as repeated addition. Finally, this approach prepares the informal introduction of real numbers, although it is also a weakness that it almost makes real numbers appear as a triviality. Klein's point is not that visual approaches should simply replace the first two, but that the teacher should be aware of the advantages and disadvantages of such visualisations, and not least their theoretical limitations. 
Of course, Klein has more than the above to say about fractions, decimals and real numbers. However, he does not give specific advice on how to teach the subject. Some of his more general remarks can help us to see how the three models could function together. For instance, rules such as

$$
\frac{a}{b} \cdot \frac{c}{d}=\frac{a c}{b d}
$$

cannot be visualized at once using the line, while the special cases

$$
a \cdot \frac{c}{d}=\frac{a c}{d}
$$

can (using repeated addition). The general case can, of course, be easily proved using M1, M2 and M4, or it is (in the most formal approach) simply a definition of fraction multiplication.

In another context, Klein (2016, vol. I, pp. 82-83) observes that one can identify two mutually complimentary "plans" (strategies) in the history of mathematics. Plan A seeks the pure, clear and synthetic development of a subject. Plan B is more chaotic, working with problems based on intuition and more or less imperfect methods. One can imagine a similar mutually supporting role of intuition and formalization in teaching. Klein (2016, vol. I, p. 32) himself opposes the idea of teaching the formal and intuitive approach to fractions in isolation from each other: it is questionable whether such a separation would be desirable pedagogically.

Of course, almost one hundred years after Klein's death, we have thousands of studies and practical proposals, e.g. in the form of textbooks, about how to teach fractions. One of the most persistent problems identified is the difficulty students have to conceive of fractions as representations of one number, rather than as a division of integers. The advent of electronic calculators have led many teachers to believe that the arithmetic of fractions is somehow obsolete; after all, the computation

$$
\frac{2}{15} \cdot \frac{9}{10}=0.12
$$

can be done in a few seconds with any such a device. Slightly more advanced devices may even give the result in reduced fractional form. But this reasoning fails to look ahead in the curriculum. At some point, he will encounter the need for algebraic identities such as

$$
\frac{1-b^{2}}{1+b}+\frac{b^{2}-1}{b-1}=2 \text {. }
$$

Without mastering - at least in practice the formal rules which govern the arithmetic of fractions - namely (A1)(A4),(M1)-(M3) and (D) mentioned above - the student may soon find himself faced with an overwhelming amount of meaningless "rules" to memorize, and may - as many do - not succeed to operate in a useful and correct way with such expressions. And this handicap will definitively exclude him from most of the subsequent work with (for instance) functions, calculus, and mathematical models in other subjects.

Whether we like them or not, the "rules" (A1)-(A4), (M1)-(M4) and (D) govern all of arithmetic. There are, in principle, no more rules to learn; all other rules are derived from them. They therefore need to be thoroughly learned 
and understood by primary school teachers. They should not be taught to students in isolation, but are to be learned in the context of fractional arithmetic, in an appropriate sequencing and mixture with intuitive and alternative representations of rational numbers. And this brings us to another point, which does not only concern individual teacher knowledge: Curriculum.

\section{CURRICULUM}

One of the major breakthroughs in mathematics education research on curriculum has been "the theory of didactical transposition", developed by several French scholars, especially Verret (1975) and Chevallard (1991). It was motivated by the need to come to grips with certain effects of two major historical events:

(1) The curriculum reform known in many Western countries as "New Math", which was both implemented and retracted rather suddenly in these countries within a period of around 20 years (1965-1985);

(2) The profound transformations of universities in roughly the same period, as universities expanded massively both in terms of students and faculty.

Both events are often linked to the socalled Sputnik shock, caused in Western nations by the Soviet launch of the Sputnik I missile in 1957, which led them to massively scale up their efforts in research and education within physics and closely related fields such as mathematics. As a result, curricula were reformed profoundly, with the aim of aligning them with the latest developments in science - which, for mathematics, implied to replace classical foundations of elementary education such as Euclid's Elements and practical Arithmetic, by more abstract and recent constructions like set theory. The author of this paper witnessed these reforms at first hand, being presented, for instance, with Venn diagrams and informal versions of cardinality in grade 1 , and by being treated, in high school, to rigorous Analysis and elements of abstract Algebra. There are many possible interpretations of how and these reforms were implemented, and why they were subsequently retracted (see e.g. Philips, 2015), but the effects of these abrupt changes led scholars such as Chevallard (1991) to reflect more deeply on the role which teachers occupy in educational institutions, from elementary school to university. In particular, the notion that school mathematics is somehow constituted by a selection of scholarly mathematics, which is then smoothly passed onto students by the teacher, cannot account for the profound transformations - sometimes, even disfigurations - which occur in the process.

The notion of fractions is an excellent example. In the preceding section, we have already briefly touched upon the current scholarly model of fractions, which is closely linked to the axiomatization of number systems: the field of rational numbers is constructed 
from the integral domain of integers as its unique field of fractions (this is explained in detail in almost any introductory university textbook on abstract Algebra). But in school, numbers cannot be taught according to this beautiful Plan A: not only are abstractions such as quotient space and axioms out of reach considering the age when students need to become acquainted with fractions (and decimals), it is also very distant from the social practices and informal models which the teaching needs to build on and relate to. One can still defend the point of view that teachers at this level should be profoundly acquainted with the scholarly model (while the present organization of primary school teacher education makes it unrealistic in many cases); but this does certainly not suffice to succeed in realizing the inevitable "Plan B approach" outlined above. One of the deeper difficulties is to establish sound and meaning-generating relations between fractions and the many-faceted idea of proportion, which occurs in both elementary arithmetic, algebra and geometry. At the same time, a frequently observed effect of didactic transposition is that of desynchretisation (Verret, 1975, p. 140): topics are taught in isolation from each other, as the teacher follows the curriculum bit by bit, but fails to establish meaningful relationships between them. Moreover, "bits" of mathematical praxis may be left from earlier curricula, which no longer make sense, either in relation to the rest of the curriculum, or just to the individual teacher (see Wijayanti and Bosch 2018).

In other words, even the best professional preparation and working conditions of teachers leaves with a curriculum that can be more or less favorable to create successful learning conditions for their students. In her doctoral thesis, Wijayanti (2017) investigates a part of the didactical transposition of a collection of mathematical sectors linked to the notion of proportion, namely the ways in which these sectors appear and are connected in the Indonesian curriculum, especially types of tasks in the officially approved textbooks for lower secondary school. One of the interesting discoveries in her work is that while the textbooks adequately mirror the types of tasks which appear in national examinations, they also fail to relate sectors occurring in different domains, such as arithmetic (where the topic is closely connected to fractions) and geometry (where similarity and congruence are the official labels). Similar disconnections are found in the curricula of other countries (Wijayanti and Bosch, 2018). When combined with Putra's results concerning teacher students' mathematical and didactical knowledge in connection to fractions, one cannot help to be concerned, given the knowledge we have of the detrimental effects which insufficient acquaintance with fractions can have on the students' success with more advanced part of the curriculum, and subsequently in realizing their potential in 
professional situations and careers where mathematical competence is required.

\section{CONCLUSIONS}

Few will deny, today, that education and not least mathematical education is a sine qua non for sustaining and developing human societies. When it comes to mathematics and science, we have, in fact, massive evidence from financial analyses, carried out by the OECD-PISA (2010), that the expected returns of higher education in these fields are very high. So for decisionmakers, the question should be: how to make these investments? What will work?

The answer might not be so simple. The chain of causality may be long and doubtful between investments in, say, primary school teacher education, and improved results in terms of economic growth. What is more, any investment could conceivably fail because the wrong measures are invested in. For instance, better preparation of teachers may be at least partly wasted if other elements of the educational system provide obstacles for their students' success, whether these elements are incoherent curricula, inequitable access to higher education, or a lack of opportunities for teachers to engage in professional growth and curriculum development based on practice. At the same time there are unquestionable differences among countries when it comes to childrens' success in school mathematics. Thus, we need deeper insights into what distinguishes

high-performing educational systems from less well performing ones. At the same time, experimentations of hypotheses for effective improvements - based on comparative studies involving highperforming systems - are needed to gauge the validity of such hypotheses. For instance, there is rather massive research evidence that some East Asian educational systems perform well due to the opportunities they offer teachers for in-service professional development, and for engaging in bottom-up development of curriculum in a large sense (see e.g. Miyakawa and Winsløw, 2019, for one instance of such research and further references for the case of Japan and mathematics education).

What is certain is that small-scale studies of highly specific educational practices - including comparative studies and innovative experiments - must be combined and efficiently connected with large-scale studies. The latter are, almost always, purely descriptive, and can thus only produce broad hypotheses and establish relatively general facts. In short, we need to pursue a systemic (institutional, cultural) perspective on research, particularly in an area like mathematics education where societies around the world share many challenges and aspirations, but where at the same time we know for sure that broad solutions devised far from teaching practice have failed to provide the progress needed. 


\section{REFERENCES}

Chevallard, Y. (1991). La transposition didactique - du savoir savant au savoir enseigné (first edition, 1985). Grenoble: La Pensée Sauvage.

Chevallard, Y. (1999). L'analyse des pratiques enseignantes en théorie anthropologique du didactique. Recherches en Didactique des Mathématiques 19(2), 221-266.

Durand-Guerrier, V., Winsløw, C., \& Yoshida, H. (2010). A model of mathematics teacher knowledge and a comparative study in Denmark, France and Japan. Annales de Didactiques et de Sciences Cognitives 15, 141-166.

Hill, H., Rowan, B., \& Ball, D. (2005). Effects of Teachers' Mathematical Knowledge for Teaching on Student Achievement. American Educational Research Journal 42(2):371-406

Kilpatrick, J. (1992). A history of research in mathematics education. In D. Grouws (Ed.), Handbook of research on mathematics research and teaching, pp. 3-39. New York: MacMillan.

Klein, F. (2016/1908). Fundamental Mathematics from a Higher Standpoint, I. Translated by G. Schubring. Berlin: Springer.

LMS (1995). Tackling the mathematics problem. Birmingham: London Mathematical Society. Retrieved from

http://mei.org.uk/files/pdf/Tacklin $\mathrm{g}$ the Mathematics Problem.pdf

Miyakawa, T., \& Winsløw, C. (2019). Paradidactic infrastructure for sharing and documenting mathematics teacher knowledge: a case study of "practice research". Journal of Mathematics Teacher Education 22(3), 281-303

OECD-PISA (2010). The high cost of low educational performance - the long-run economic impact of improving PISA outcomes. Retrieved from https://www.oecd.org/pisa/44417 824.pdf

Philips, C. (2015). The New Math - A political history. Chicago: U. of Chicago Press.

Putra, Z. H. (2018). A comparative study of Danish and Indonesian preservice teachers' knowledge of rational numbers (Doctoral dissertation). University of Copenhagen, Denmark, Retrieved from

https://www.ind.ku.dk/begivenhed er/2018/putra/Thesis Zetra Putra. pdf

Siegler, R. S., Duncan, G. J., Davis-Kean, P. E., Duckworth, K., Claessens, A., Engel, M., Susperreguy, M., \& Chen, M. (2012). Early Predictors of High School Mathematics Achievement. Psychological Science, 23(7), 691697. https://doi.org/10.1177/0956 
797612440101

Stigler , J., \& Hiebert, J. (1999). The Teaching Gap: Why our schools are falling behind and what we can learn from Japanese and Chinese education. New York: Greenwood Press.

Tatto, M. T., Smith, W. M., Rodriguez, M. C., Reckase, M., \& Bankov, K. (Eds.) (2018). Exploring the Mathematical Education of Teachers Using TEDS-M Data. Switzlerland: Springer.

Verret, M. (1975). Le temps des études I. Paris: Librairie Honoré Champion.

Wijayanti, D. (2017). A Praxeological Study of Proportionality in Mathematics Lower Secondary Textbooks (Doctoral dissertation). University of Copenhagen,
Denmark, Retrieved from https://www.ind.ku.dk/begivenhed er/2017/wijayanti/PhD thesis Dya na Wijayanti.pdf

Wijayanti, D., \& Bosch, M. (2018). The evolution of the knowledge to be taught through educational reforms: the case of proportion. In Y. Shimizu and R. Vithal (Eds.), School Mathematics Curriculum Reforms: Challenges, Changes and Opportunities. Proceedings of ICMI Study 24, pp. 173-180. Retrieved from https://www.mathunion.org/filead min/ICMI/ICMI\%20studies/ICMI $\% 20$ Study\%2024/ICMI\%20Study $\% 2024 \% 20$ Proceedings.pdf 